\title{
Formas Plurais no Franchising de Alimentos: Evidências de Estudos de Caso na França e no Brasil
}

\author{
Vivian Lara S. Silva \\ Paulo Furquim de Azevedo
}

\section{ResUMo}

O problema de formas plurais é importante tema de interesse na literatura dedicada ao franchising. A coexistência de lojas próprias e unidades franqueadas em uma mesma rede é fato bem conhecido, merecendo a grande atenção que vem recebendo dos pesquisadores. Acontece, porém, que formas organizacionais no franchising são mais diferenciadas do que sugere a literatura. De fato, informações oriundas de 21 estudos de caso, realizados na França e no Brasil, evidenciam a existência, em acréscimo à hierarquia (lojas próprias), de três opções de contratos de franquia: 1) franquia convencional; 2) franquia parcial e 3) contrato de locação de gerência, os quais diferem entre si em termos da exigência de capital, incentivo e divisão de riscos. É observado o emprego combinado de lojas próprias, com um ou mais dos formatos contratuais identificados, referindo-se a um portfólio de formas organizacionais na regência das transações. $\mathrm{O}$ ambiente institucional revela-se a principal variável explicativa das particularidades observadas no uso de formas plurais na França e no Brasil. Em especial, tem-se o sistema legal e as incertezas relacionadas às decisões judiciais como as principais razões pelas quais as redes com operação no mercado brasileiro não exploram por completo a diversidade dos contratos de franquia como identificado na França/Europa.

Palavras-chave: formas plurais; contratos de franquia; ambiente institucional; valor de marca.

\begin{abstract}
Plural forms are an important subject in the franchising literature. The co-existence of franchised and company-owned outlets in the same chain is well-known fact, deserving the huge attention it received from researches. Nevertheless organizational forms in franchising are more diverse than these studies propose. In this paper we describe three types of franchising contracts, observed in a set of 21 case studies in France and Brazil, that differ in terms of capital requirement, incentives and risk sharing. Franchisors frequently combine company-owned outlets with one or more of these franchising contracts, using a portfolio of organizational forms to govern the transaction with his/her outlets. The multi-case study suggests institutional environment as the main variable to explain the differences in the use of plural forms in France and Brazil. Particularly, we submit that legal system and the uncertainty regarding court decisions are the main reasons why in Brazil franchise chains do not fully explore the diversity of franchising contracts.
\end{abstract}

Key words: plural forms; franchising contracts; institutional environment; brand name value. 


\section{INTRODUÇÃO}

O franchising caracteriza-se por uma forma organizacional complexa, composta por partes legalmente distintas: uma parte central, detentora da marca e do conhecimento de gestão do negócio (o franqueador), e múltiplos agentes econômicos (os franqueados).

A relação estabelecida entre franqueado e franqueador é regida pelo contrato de franquia, em que o franqueador acorda em transferir a seus franqueados o direito de uso e exploração de sua marca na produção ou venda de produtos ou serviços, por um período de tempo determinado em região geográfica específica. Adicionalmente, o franqueado também pode beneficiar-se da oferta por parte do franqueador de programas de treinamento e reciclagem, além de outros serviços, como assistência técnica e comercial contínuas. Em contrapartida, o franqueador recebe uma soma monetária fixa inicial (taxa de franquia), acrescida de uma parcela das vendas da unidade franqueada, usualmente sob a forma de taxas variadas, caso dos royalties, taxa de publicidade ${ }^{(1)}$, entre outras ${ }^{(2)}$. Adicionalmente, o franqueado também pode contribuir com outros ativos, como recursos financeiros, habilidade gerencial ou conhecimento sobre mercados locais. Forma-se, assim, uma rede em que franqueador e franqueado se associam sob a motivação de ganhos bilaterais no uso compartilhado de ativos tangíveis ou intangíveis, muitos dos quais específicos à relação comercial firmada: como a marca e o conhecimento adquirido na atividade franqueada, em termos das práticas organizacionais e administrativas de gestão.

$\mathrm{Na}$ operacionalização dos estabelecimentos sob a marca franqueada, o franqueador pode optar por uma rede $100 \%$ franqueada ou por uma rede mista, em que parte dos estabelecimentos são de sua propriedade (lojas próprias). Além disso, o franqueador pode empregar diferentes modalidades de contratos em sua relação com franqueados. Em outras palavras, em acréscimo à integração vertical (lojas próprias), o franqueador ainda pode optar por um leque de diferentes contratos de franquia na regência de seu relacionamento com os franqueados.

Embora essa diversidade de formas organizacionais seja comum em redes de franquias, curiosamente a literatura internacional trata da dicotomia entre lojas próprias e unidades franqueadas, implicitamente assumindo que os contratos de franchising são homogêneos. Em contraposição, este artigo investiga a diversidade de formas organizacionais utilizadas pelos franqueadores de marcas de alimento na gestão de suas redes. Para tanto é apresentado um estudo multicaso conduzido na 
França e no Brasil, permitindo avaliar se as diferenças no ambiente institucional desempenham papel relevante na escolha da diversidade de contratos de franquia.

Como usual em estudos multicaso (Yin, 1989), a coleta dos dados foi baseada em entrevistas semi-estruturadas dos gerentes das áreas de suprimento e de expansão das redes. No total, 21 estudos de caso foram conduzidos (sete na França e 14 no Brasil), oriundos de cinco importantes segmentos do franchising de alimentos: 1) cafeterias, 2) doces \& chocolates, 3) fast food, 4) grelhados e 5) produtos finos. Na França, foi investigada a atuação das redes Grill Courtepaille, La Boucherie, ambas do segmento de grelhados; Jeff de Bruges, doces \& chocolates; e Comtesse du Barry, atuante no segmento de produtos finos, é especializada em foie gras, clássico segmento da cuisine francesa. A amostra também inclui as operações no mercado francês do grupo italiano Segafredo Zanetti, cafeterias; e da rede belga Quick, fast food. No Brasil, foram analisadas as redes brasileiras Fran's Café; Café Pelé; Café do Ponto, recentemente adquirida pela americana SaraLee; e Casa do Pão de Queijo; todas atuantes no segmento de cafeterias. Além das redes Habib's; China in Box; Vivenda do Camarão, fast food; Bon Grillê, grelhados; Kopenhagen, produtos finos, dedicada à comercialização de chocolates; e Amor aos Pedaços, doces \& chocolates. Também foram investigadas as operações no Brasil das redes americanas The Nutty Bavarian, Dunkin'Donuts, ambas atuantes no segmento de doces \& chocolates; e Arby's, fast food. Fechando a amostra, foram ainda comparadas as operações da rede americana de fast food McDonald's em ambos os mercados, francês e brasileiro.

A escolha das redes foi baseada em alguns critérios-chave. Partindo dos segmentos mais relevantes do franchising de alimentos na França e no Brasil, procurou-se selecionar as principais redes a partir do valor comparativo de suas marcas, mensuradas com base na representatividade comparativa das redes em seus segmentos, de sua estabilidade (trajetória, em anos, antes e depois do franchising), bem como do grau de dispersão geográfica (Aaker, 1998). Adicionalmente, a escolha foi balizada no sentido de viabilizar uma análise comparada em cada um dos referidos países de redes com atuação em um mesmo segmento. Particularmente, destaca-se a análise comparada do McDonald's, permitindo capturar melhor os efeitos da diversidade institucional sobre o padrão de coordenação upstream, adotado pelas redes. Por fim, a escolha de uma análise empírica comparada do franchising francês e brasileiro deve ser interpretada à luz da relevância histórica e econômica destes dois países ao franchising internacional, bem como da diversidade institucional destes mercados, no que tange, por exemplo, à regulação dos contratos de franquia, política de defesa da concorrência, efetividade do judiciário na garantia de contratos, normas e convenções sociais, entre os quais hábitos alimentares etc. 
$\mathrm{O}$ artigo divide-se em três seções, além desta introdução. A próxima seção resgata o debate econômico da convivência de formas plurais no franchising. Na seqüência, a terceira seção dedica-se à análise comparada do estudo multicaso conduzido na França e no Brasil. A quarta e última seção sumaria as principais conclusões, implicações gerenciais e perspectivas para estudos futuros.

\section{Franchising e o Problema de Formas Plurais}

Os potenciais riscos de má utilização da marca por parte do franqueado afetam sob várias maneiras a organização de empresas que optam pelo franchising. Em síntese, a existência de múltiplos agentes dispersos geograficamente (franqueados), cujos rendimentos provêm da exploração coletiva de um mesmo ativo (marca franqueada), resulta freqüentemente em problemas de incentivo e em externalidades (horizontais e verticais) no uso deste ativo (Bai \& Tao, 2000a; Lafontaine \& Raynaud, 2002). Estes e outros problemas de risco moral (moral hazard), segundo a Teoria da Agência ${ }^{(3)}$, seriam atenuados por meio dos contratos de incentivo, caso dos contratos de franquia.

Sob este arranjo, o Principal, representado pela figura do franqueador, busca a motivação do Agente, o franqueado, por meio do recebimento dos lucros residuais das operações da unidade franqueada ${ }^{(4)}$ : se o negócio vai além das estimativas preliminares, o franqueador se beneficiará das vendas excedentes, mas se o negócio não estiver sendo muito lucrativo, não caberá exclusivamente ao franqueado todo o ônus do prejuízo. Motivado pelo lucro residual da unidade franqueada, o franchising garantiria ao Agente maiores incentivos em melhor esforçar-se no desempenho de suas atividades ${ }^{(5)}$, trabalhando com maior afinco conforme deseja o Principal, já que ele (o Agente) será o maior beneficiado de suas ações. Em decorrência direta de sua maior eficiência no alinhamento dos interesses das partes, a grande vantagem comparativa do franchising com relação a uma expansão verticalizada (estruturada em lojas próprias, em que o Agente é tipicamente representado pela figura de um gerente com remuneração fixa), referese à redução dos custos de monitoramento e de controle da comercialização. Nesses moldes, desde que o crescimento de uma rede está intrinsecamente associado a maiores custos de monitoramento e de controle, a opção de expansão via franchising deveria ser preferida em relação a lojas próprias ${ }^{(6)}$. Na contramão desta clássica premissa da literatura, chama a atenção o fato de as organizações que utilizam ofranchising sustentarem, em um mesmo ambiente institucional e competitivo, um percentual estratégico de lojas próprias em acréscimo às unidades franqueadas. Esta constatação estimulou o interesse da academia pelo problema da pluralidade de formas organizacionais no franchising, referindo-se ao fato de 
os atores econômicos não se restringirem à escolha de uma única estrutura de governança, mas escolherem um portfólio de mecanismos, combinando um leque (um mix) de diferentes formas contratuais para reger seu conjunto de transações ${ }^{(7)}$.

O problema de formas plurais não deve, porém, ser entendido como particularidade do franchising, revelando-se, na verdade, generalizado ${ }^{(8)}$. Esse é o caso, por exemplo, de empresas cujo abastecimento de insumos é parcialmente produzido por unidades próprias (integração vertical parcial para trás); ou mesmo de empresas que utilizam canais de comercialização que implicam diferentes estruturas de governança, como lojas próprias e vendas em varejistas (integração vertical parcial para frente); ou ainda as que estruturam contratos de trabalho distintos para o exercício da mesma função. Os exemplos são muito variados e comuns, indo desde a produção de cana própria e de terceiros, por parte das usinas de açúcar e álcool, até a venda direta ou em consignação de livros e CDs.

O franchising, por sua vez, oferece um caso de formas plurais de fácil tratamento empírico, por ser usual a utilização simultânea de lojas próprias e lojas franqueadas como meio de distribuição. Efetivamente, esta configuração pode ser entendida como integração vertical parcial para frente, de tal modo que a mesma transação pode utilizar-se de diferentes estruturas de governança. A análise do modo como se organiza o franchising, particularmente no que se refere à proporção de lojas próprias e lojas franqueadas, reporta-se, consequientemente, ao problema de formas plurais, podendo ser amparada pela literatura que investiga esta questão. Embora a literatura a este respeito ainda não esteja consolidada, há diversos argumentos que justificam a convivência de estruturas de governança distintas, regendo transações similares.

Em um primeiro grupo, há dois conjuntos de argumentos que são compatíveis com o difundido modelo de Williamson (1991), adaptando-o para a explicação da heterogeneidade contratual. Essencialmente, o que determina a escolha de uma dada estrutura de governança, e.g. lojas próprias ou franchising, são as características da transação. Formas organizacionais podem ser plurais, ou seja, observa-se o uso de mais de uma estrutura de governança, se as transações forem diversas, distinguindo-se em pelos menos um de seus clássicos atributos: especificidade de ativos, incerteza e frequiência. Por exemplo, um franqueador poderia utilizar-se de lojas próprias em áreas em que a especificidade de ativos seja superior, em que há maior dependência mútua entre o franqueador e as atividades do ponto de venda; ou em que a incerteza de sucesso do empreendimento inviabilize a adoção de formas híbridas, como a franquia (Aoki, 1990). As diversas relações entre o franqueador e as lojas constituiriam transações distintas, com atributos distintos e, portanto, associadas a estruturas de governança distintas. 
Igualmente compatível com o modelo de Williamson (1991) é a explicação da heterogeneidade contratual, fundada nos limites cognitivos dos agentes econômicos. Em resumo, há problemas de mensuração dos atributos das transações, assim como de solução do complexo problema de escolha das estruturas de governança, o que pode conduzir a diferentes resultados. Em outras palavras, dado o pressuposto de racionalidade limitada, não há solução determinística, uma vez que, para níveis próximos dos atributos das transações, não é possível identificar a melhor solução, tampouco distinguir precisamente as transações; portanto a heterogeneidade das estruturas de governança decorreria da incapacidade de os agentes escolherem a solução de fato mais eficiente ${ }^{(9)}$.

Contradizendo o entendimento deste primeiro grupo, um segundo conjunto de argumentos dedicado à investigação do problema de formas plurais sugere a escolha de diferentes estruturas de governança na regência de transações similares, que compartilham dos mesmos atributos. Situação que parece ser mais adequada para o caso do franchising, dada a sua natureza de um contrato de adesão. Admite-se que transações com os mesmos atributos podem resultar em formas plurais, ou seja, no caso específico de franquias, lojas próprias convivendo com lojas franqueadas.

Partindo deste entendimento, parte da literatura considera transitório o emprego de formas plurais no tempo, devendo prevalecer uma ou outra estrutura de governança. Este é o caso dos modelos de Gallini e Lutz (1992) e Scott (1995), para quem lojas próprias desempenhariam o papel de sinalizar características relevantes dos franqueadores. Em outras palavras, em um mundo em que os potenciais franqueados conhecem perfeitamente o negócio e os serviços prestados pelos franqueadores, as franquias seriam mais apropriadas para governar a transação entre ambos. No entanto o fato de um potencial franqueado não ter confiança na qualidade do franqueador (em linguagem técnica, há uma assimetria de informação a respeito do tipo do franqueador), como, por exemplo, qualidade dos serviços de apoio, práticas de renegociação etc. faz com que a transação não se efetue, podendo gerar um problema de seleção adversa ${ }^{(10)}$. Com a finalidade de induzir o franqueamento, o franqueador pode manter algumas lojas próprias, a fim de sinalizar a qualidade de seus serviços, reduzindo o problema derivado da assimetria informacional. Com o passar do tempo, o franqueador desenvolve reputação a respeito de seus serviços ou de outros comportamentos pós-contratuais, o que desempenha o papel de sinalização em substituição às lojas próprias. Como consequiência, o desenvolvimento de uma rede de franquias levaria à progressiva redução de lojas próprias, resultando no predomínio absoluto de lojas franqueadas.

Ainda no grupo de argumentos que prediz a transitoriedade do emprego de formas plurais, outra vertente de análise defende exatamente a trajetória inversa. 
Na literatura voltada ao estudo do franchising, é de grande relevância a hipótese de recuperação da propriedade (ownership redirection), ou seja, de crescimento inicial pelo franchising que, com o passar do tempo, seria progressivamente substituído por lojas próprias, resultando no domínio absoluto dessa estrutura de governança na plena maturidade do negócio (Dant, Paswan, \& Stanworth, 1996). Este argumento funda-se na tese de que o franchising é um meio de captar recursos - humanos e de capital - de modo rápido, superando os constrangimentos externos dados pelo sistema de crédito e de contratação de pessoal. Com o passar do tempo e com a consolidação do negócio, esses constrangimentos externos perderiam a relevância, atenuando a motivação para a utilização do franchising, levando à sua progressiva substituição por lojas próprias.

Por fim, um terceiro grupo de argumentos defende a estabilidade do emprego de formas plurais no franchising, condição esta dependente da inexistência de mudanças exógenas nas condições básicas para a escolha das estruturas de governança ${ }^{(11)}$. Na literatura dedicada aos contratos de franquia, a tese mais defendida na interpretação da estabilidade de formas plurais reporta-se à hipótese de complementaridade das estruturas de governança ${ }^{(12)}$. Mais do que concorrentes na governança de transações similares - ponto que deriva do insight original de Coase (1937) e que ainda representa um dos principais fundamentos da Nova Economia Institucional (NEI), em especial da Economia dos Custos de Transação (ECT) - as estruturas seriam complementares, devendo haver situações em que parte da função de um contrato seria justamente contribuir para a eficiência de outra forma contratual. A decisão pela manutenção de um percentual ótimo e estável de lojas próprias ao longo do tempo pode, assim, ser interpretada, enquanto complementar ao funcionamento das unidades franqueadas, no sentido de prover maior controle e capacidade de barganha ao franqueador sobre seus franqueados (Michael, 2000), especialmente na redução das chances de um comportamento oportunista no uso compartilhado da marca franqueada. Em outras palavras, o mix contratual representaria um mecanismo de controle do franqueador sobre as operações do franqueado, empregado com a finalidade de diminuir as possibilidades de uma má utilização da marca ${ }^{(13)}$.

Embora a literatura econômica tenha avançado nos últimos anos na investigação do problema da pluralidade de formas organizacionais no franchising, esta vem sendo restrita à dicotomia loja própria-unidade franqueada, pouco se discutindo a hipótese do emprego de diferentes estruturas - e de sua complementaridade - na relação entre franqueador e pontos de venda. O presente artigo aborda este ponto, analisando a escolha do portfólio de estruturas de governança que regem a relação entre os gestores de uma rede e seus pontos de venda. 


\section{Ambiente Institucional e seus Efeitos nos Contratos de FRANQUIA}

Como discutido na seção anterior, o problema de formas plurais é importante tema de interesse na literatura dedicada ao franchising. A coexistência de lojas próprias e unidades franqueadas em uma mesma rede é fato bem conhecido, merecendo a grande atenção que vem recebendo dos pesquisadores ${ }^{(14)}$. Acontece, porém, que formas organizacionais no franchising são mais diferenciadas do que sugere a literatura ${ }^{(15)}$. De fato, em acréscimo à hierarquia (lojas próprias), o estudo multicaso conduzido no Brasil e na França evidencia três diferentes contratos de franquia: 1) franquia convencional; 2) franquia parcial; e 3) contrato de locação de gerência (vide Tabela 1).

O contrato de franquia convencional é o tradicionalmente referenciado na literatura ${ }^{(16)}$. Neste arranjo, o franqueador transfere ao franqueado a integralidade dos investimentos iniciais de instalação e de pessoal da unidade franqueada: compra ou locação do imóvel, aquisição dos equipamentos, materiais, mobiliários e luminosos necessários à montagem e decoração da unidade bem como despesas de seleção, treinamento e contratação da equipe de funcionários. Adicionalmente, o franqueado, que pode exercer diretamente o gerenciamento de sua unidade ou delegá-la a terceiros, paga ao franqueador uma taxa inicial de adesão (taxa de franquia) em acréscimo à transferência periódica de um percentual do faturamento da unidade, na forma de royalties e taxas afins, como de publicidade.

Diferentemente da franquia convencional, no contrato de franquia parcial os investimentos iniciais da unidade são compartilhados entre as partes. $\mathrm{O}$ franqueador assume as despesas com o imóvel, detendo o controle sobre o ponto comercial, enquanto o franqueado arca com as despesas de decoração e montagem, somadas às de seleção, treinamento e contratação de sua equipe. Em contrapartida, além da taxa de franquia e dos royalties, o franqueado transfere ao franqueador uma parcela adicional do faturamento de sua unidade na forma de taxa de aluguel.

Por fim, no contrato de locação de gerência, o franqueador tipicamente arca com a integralidade dos investimentos iniciais da unidade franqueada, transferindo ao franqueado unicamente o controle gerencial do ponto comercial. Em troca, o franqueado paga ao franqueador uma taxa de administração, também calculada com base em percentual do faturamento da unidade, em acréscimo aos royalties e taxa de aluguel, sendo a taxa de franquia não necessariamente efetuada. Nesses moldes, a figura do franqueado mais se 
assemelha à de um gerente de loja própria com rendimentos variáveis, conforme seu desempenho. A Tabela 1 sintetiza as principais características de cada uma das estruturas de governança identificadas no estudo multicaso conduzido na França e no Brasil.

Uma importante distinção entre os mecanismos de governança identificados é o papel exercido no equacionamento das restrições organizacionais na obtenção de capital. Enquanto na franquia convencional o franqueado arca com a integralidade dos investimentos iniciais de sua unidade, no contrato de locação de gerência não há imobilização de seu capital, embora o incentivo decorrente dos lucros residuais seja também transferido ao franqueado. Nestes termos, a existência do contrato de locação de gerência é forte evidência de que o aporte de capital à rede não é a única razão para o franchising argumento, porém, que permanece relevante para a escolha do contrato de franquia convencional.

Partindo dessa premissa, seria de se esperar que a menor eficiência do mercado de capitais brasileiro e, conseqüentemente, as maiores restrições ao sistema de crédito, implicariam maior interesse dos franqueadores atuantes no Brasil pela prática do contrato de franquia total, em detrimento dos outros formatos. $\mathrm{Na}$ França, por sua vez, em função da menor restrição ao sistema de crédito, o papel do franchising, enquanto mecanismo de captação de recursos financeiros deveria ser atenuado, estimulando a prática pela franquia parcial e pela locação de gerência. Conforme ilustra a Tabela 2, esta proposição foi comprovada no estudo multicaso conduzido nos mercados brasileiro e francês ${ }^{(17)}$.

Conforme ilustra a Tabela 2, das sete redes analisadas na França, apenas a Grill Courtepaille e a Jeff de Bruges declararam não empregar a franquia parcial ou o contrato de locação de gerência. Em decorrência da necessidade de viabilizar a expansão pretendida por meio do capital de terceiros, essas duas redes, independentemente do mercado considerado, estruturam o franqueamento de seu sistema por meio, exclusivamente, da franquia total. Opondo-se a este posicionamento, as demais redes analisadas no mercado francês, Comtesse du Barry, La Boucherie e Segafredo Zanetti, não descartam potenciais candidatos com restrições financeiras, disponibilizando o franqueamento de suas marcas também por meio do contrato de locação de gerência. No extremo, a rede Quick, em seus principais mercados (França, Bélgica e Luxemburgo), adota exclusivamente os contratos de franquia parcial e locação de gerência, não praticando a franquia total. 


\section{Tabela 1: Síntese das Características Contratuais do Portfólio de Mecanismos Identificado no Franchising Francês e Brasileiro}

\begin{tabular}{|c|c|c|c|c|c|c|}
\hline \multirow{2}{*}{$\begin{array}{c}\text { Formato } \\
\text { Contra- } \\
\text { tual }\end{array}$} & \multicolumn{5}{|c|}{ Características } & \multirow{2}{*}{$\begin{array}{l}\text { Consequiên- } \\
\text { cias }\end{array}$} \\
\hline & Investimento & $\begin{array}{l}\text { Esquema de } \\
\text { Pagamentos }\end{array}$ & Controle & $\begin{array}{c}\text { Lucro } \\
\text { Residual }\end{array}$ & $\begin{array}{c}\text { Aversão ao } \\
\text { Risco }\end{array}$ & \\
\hline $\begin{array}{c}\text { franquia } \\
\text { conven- } \\
\text { cional }\end{array}$ & $\begin{array}{l}\text { integralidade } \\
\text { dos } \\
\text { investimentos } \\
\text { iniciais sob } \\
\text { responsabilida } \\
\text { de do } \\
\text { franqueado }\end{array}$ & $\begin{array}{l}\text { taxa de adesão } \\
\text { fixa e taxa } \\
\text { variável } \\
\text { conforme o } \\
\text { faturamento da } \\
\text { unidade } \\
\text { franqueada } \\
\text { (royalties e } \\
\text { taxas afins) }\end{array}$ & $\begin{array}{c}\text { ponto } \\
\text { comercial sob } \\
\text { controle do } \\
\text { franqueado } \\
\text { (compra ou } \\
\text { locação do } \\
\text { imóvel) }\end{array}$ & $\begin{array}{c}\text { transferido } \\
\text { ao } \\
\text { franqueado }\end{array}$ & $\begin{array}{l}\text { franqueado } \\
\text { está mais } \\
\text { sujeito a } \\
\text { riscos }\end{array}$ & $\begin{array}{c}\text { Maior } \\
\text { vantagem na } \\
\text { captação de } \\
\text { recursos de } \\
\text { capital e } \\
\text { humanos e na } \\
\text { redução de } \\
\text { problemas de } \\
\text { risco moral de } \\
\text { esforço } \\
\end{array}$ \\
\hline $\begin{array}{c}\text { franquia } \\
\text { parcial }\end{array}$ & $\begin{array}{l}\text { investimentos } \\
\text { iniciais } \\
\text { divididos } \\
\text { entre as partes } \\
\text { (franqueado e } \\
\text { franqueador) }\end{array}$ & $\begin{array}{l}\text { taxa de adesão, } \\
\text { royalties e taxas } \\
\text { afins, em } \\
\text { acréscimo à } \\
\text { parcela } \\
\text { adicional do } \\
\text { faturamento da } \\
\text { unidade na } \\
\text { forma de } \\
\text { aluguel } \\
\end{array}$ & $\begin{array}{l}\text { ponto } \\
\text { comercial sob } \\
\text { controle do } \\
\text { franqueador }\end{array}$ & $\begin{array}{c}\text { transferido } \\
\text { ao } \\
\text { franqueado, } \\
\text { mas em } \\
\text { menor } \\
\text { proporção } \\
\text { em relação } \\
\text { à franquia } \\
\text { conven- } \\
\text { cional } \\
\end{array}$ & $\begin{array}{c}\text { há maior } \\
\text { divisão de } \\
\text { riscos em } \\
\text { relação à } \\
\text { franquia } \\
\text { conven- } \\
\text { cional }\end{array}$ & \multirow{2}{*}{\begin{tabular}{|} 
ao guardar a \\
essência do \\
franchising, \\
franquia \\
parcial e \\
locação de \\
gerência \\
favorecem \\
maior \\
motivação do \\
franqueado \\
em agir de \\
acordo com \\
os interesses \\
do \\
franqueador, \\
minimizando \\
custos de \\
monitoramento, \\
em \\
comparação a \\
um gerente de \\
loja própria, \\
cujos \\
rendimentos \\
são \\
independentes \\
dos esforços \\
realizados
\end{tabular}} \\
\hline $\begin{array}{l}\text { locação } \\
\text { de } \\
\text { gerência }\end{array}$ & \multirow[t]{2}{*}{$\begin{array}{c}\text { integralidade } \\
\text { investimentos } \\
\text { iniciais sob } \\
\text { responsabili- } \\
\text { dade do } \\
\text { franqueador }\end{array}$} & $\begin{array}{l}\text { taxas de adesão, } \\
\text { royalties e afins, } \\
\text { de aluguel e de } \\
\text { administração }\end{array}$ & $\begin{array}{c}\text { ponto } \\
\text { comercial sob } \\
\text { controle do } \\
\text { franqueador, } \\
\text { sendo figura } \\
\text { do franqueado } \\
\text { mais } \\
\text { aproximada a } \\
\text { de um gerente } \\
\text { de loja própria }\end{array}$ & $\begin{array}{l}\text { transferido } \\
\text { ao } \\
\text { franqueado, } \\
\text { mas em } \\
\text { menor } \\
\text { proporção } \\
\text { em relação } \\
\text { à franquia } \\
\text { parcial }\end{array}$ & $\begin{array}{l}\text { Fraqueado } \\
\text { sujeito a } \\
\text { riscos } \\
\text { elevados, } \\
\text { dados os } \\
\text { custos fixos } \\
\text { assumidos }\end{array}$ & \\
\hline $\begin{array}{l}\text { hierar- } \\
\text { quia (loja } \\
\text { própria) }\end{array}$ & & - & $\begin{array}{l}\text { franqueador } \\
\text { detém o } \\
\text { controle do } \\
\text { ponto } \\
\text { comercial, } \\
\text { sendo } \\
\text { franqueado } \\
\text { substituído por } \\
\text { gerente de } \\
\text { loja, } \\
\text { tipicamente } \\
\text { com } \\
\text { remuneração } \\
\text { fixa }\end{array}$ & $\begin{array}{c}\text { não há } \\
\text { transferên- } \\
\text { cia }\end{array}$ & $\begin{array}{l}\text { gerente } \\
\text { recebe } \\
\text { remunera- } \\
\text { ção fixa }\end{array}$ & $\begin{array}{c}\text { maiores } \\
\text { ganhos } \\
\text { comparativos } \\
\text { na proteção e } \\
\text { valorização } \\
\text { da marca } \\
\text { franqueada } \\
\text { (melhor } \\
\text { atenuando } \\
\text { problemas de } \\
\text { risco moral de } \\
\text { qualidade) }\end{array}$ \\
\hline
\end{tabular}


Tabela 2: Formato Contratual Empregado conforme Mercado de Atuação das Redes investigadas na Análise Comparada do Franchising

\section{Brasileiro e Francês}

\begin{tabular}{|c|c|c|c|c|c|}
\hline & & & Formato & Contratual & \\
\hline Redes / mercado de atuação & Segmento & $\begin{array}{c}\text { Franquia } \\
\text { Convencional }\end{array}$ & $\begin{array}{c}\text { Franquia } \\
\text { Parcial }\end{array}$ & $\begin{array}{c}\text { Locação de } \\
\text { Gerência }\end{array}$ & $\begin{array}{c}\text { Hierarquia } \\
\text { (loja } \\
\text { própria) }\end{array}$ \\
\hline Segafredo Zanetti & & & & & \\
\hline mercados-alvo & & • & & $\bullet$ & • \\
\hline outros países & & • & NE & NE & • \\
\hline Fran's Café & cafeterias & $\bullet$ & $\mathrm{NE}$ & $\mathrm{NE}$ & $\bullet$ \\
\hline Café do Ponto $\quad$ Brasil & & $\bullet$ & $\mathrm{NE}$ & $\mathrm{NE}$ & $\bullet$ \\
\hline Café Pelé & & $\cdot$ & $\mathrm{NE}$ & $\mathrm{NE}$ & $\bullet$ \\
\hline Casa do Pão de Queijo $\quad$ Brasil & & $\cdot$ & $\mathrm{NE}$ & $\mathrm{NE}$ & $\bullet$ \\
\hline Dunkin'Donuts & & & & & \\
\hline padrão mundial & & NE & • & - & - \\
\hline Brasil & doces \& & $\cdot$ & NE & $\mathrm{NE}$ & - \\
\hline The Nutty Bavarian & chocolates & $\bullet$ & $\mathrm{NE}$ & $\mathrm{NE}$ & $\bullet$ \\
\hline Amor aos Pedaços Brasil & & $\bullet$ & $\mathrm{NE}$ & $\mathrm{NE}$ & $\bullet$ \\
\hline Jeff de Bruges $\quad$ padrão mundial & & $\cdot$ & $\mathrm{NE}$ & $\mathrm{NE}$ & $\cdot$ \\
\hline Quick & & & & & \\
\hline mercados-alvo $(\mathrm{Fr}, \mathrm{Be}, \mathrm{Lu})$ & & NE & • & • & • \\
\hline outros países & & - & NE & NE & - \\
\hline McDonald's padrão mundial & & $\mathrm{NE}$ & $\cdot$ & $\cdot$ & $\cdot$ \\
\hline Brasil & fast food & $\mathrm{NE}$ & • & $\mathrm{NE}$ & • \\
\hline padrão mundial & & NE & $\cdot$ & $\cdot$ & $\bullet$ \\
\hline Brasil & & • & $\mathrm{NE}$ & $\mathrm{NE}$ & - \\
\hline China in Box $\quad$ Brasil & & $\bullet$ & $\mathrm{NE}$ & $\mathrm{NE}$ & $\bullet$ \\
\hline Vivenda do Camarão $\quad$ Brasil & & $\bullet$ & $\mathrm{NE}$ & $\mathrm{NE}$ & $\bullet$ \\
\hline Habib's & & - & $\mathrm{NE}$ & $\mathrm{NE}$ & $\bullet$ \\
\hline Grill Courtepaille & & & & & \\
\hline padrão mundial & orelbados & $\bullet$ & NE & $\mathrm{NE}$ & $\bullet$ \\
\hline $\begin{array}{cc}\text { La Boucherie } & \begin{array}{c}\text { mercados-alvo } \\
\text { outros países }\end{array}\end{array}$ & grelhados & • & $\begin{array}{l}\mathrm{NE} \\
\mathrm{NE}\end{array}$ & $\stackrel{\cdot}{\mathrm{NE}}$ & • \\
\hline Bon Grillê $\quad$ Brasil & & $\cdot$ & $\mathrm{NE}$ & $\mathrm{NE}$ & $\cdot$ \\
\hline Kopenhagen & & - & $\mathrm{NE}$ & NE & - \\
\hline $\begin{array}{r}\text { Comtesse du Barry } \\
\text { mercados-alvo } \\
\text { outros países }\end{array}$ & $\begin{array}{l}\text { produtos } \\
\text { finos }\end{array}$ & - & $\begin{array}{l}\mathrm{NE} \\
\mathrm{NE}\end{array}$ & $\stackrel{\bullet}{\mathrm{NE}}$ & • \\
\hline
\end{tabular}

*NE: Não emprega.

Curiosamente, independentemente do padrão contratual praticado em seus principais mercados pelas redes analisadas na França, a expansão da rede para outros países, particularmente com consideráveis distâncias físicas, culturais e 
econômicas, passa a ser conduzida por meio do contrato de franquia convencional. Há dois argumentos não excludentes que sustentam essa estratégia. O primeiro baseia-se na literatura de contratos, que atribui aos custos de monitoramento um importante elemento para explicar a intensidade dos incentivos que decorrem do esquema de pagamentos. Uma vez que os custos de monitoramento são mais altos quanto mais distantes forem os pontos de venda, a vantagem de utilizar um contrato de franquia convencional, em que os lucros residuais são integralmente transferidos para os franqueados, é maior quanto maior a distância. O segundo argumento baseia-se no papel do franchising como mecanismo de captação de recursos de terceiros, tendo sido expressamente apontado pelos gestores das redes analisadas, como o elemento fundamental para a escolha da franquia convencional nesses casos. Essa forma organizacional atenua o ônus da internacionalização por meio da capacidade financeira do franqueado, além de permitir a apropriação da experiência e do conhecimento do mercado local, reforçando o papel do franchising na captação de recursos humanos. Baseandose em dados secundários, o padrão contratual, evidenciado na França, também demonstra ser o praticado nos principais países europeus e nos EUA.

Por outro lado, dentre as redes analisadas no mercado brasileiro, apenas o McDonald's não restringe o franqueamento de seu sistema ao contrato de franquia total, executando um padrão condizente com o internacionalmente praticado pela rede - posicionamento a ser analisado ainda nesta seção. Diferentemente do McDonald's, a rede americana Dunkin'Donuts não executa no Brasil o seu padrão internacional de franqueamento (similar ao modelo francês), restringindo-se à prática do contrato de franquia total. Da mesma forma, a rede brasileira Habib's vem mantendo, ao longo do tempo, a operacionalização de seu franqueamento por meio exclusivamente da franquia total, tendo sido este o padrão obedecido pelo Habib's em sua internacionalização. Este também é o padrão identificado nas redes Amor aos Pedaços, Bom Grillê, China in Box, Kopenhagen, The Nutty Bavarian e Vivenda do Camarão, bem como pelos principais nomes do coffeeshop brasileiro, Fran's Café, Café do Ponto, Café Pelé e Casa do Pão de Queijo, além de também ter sido o padrão empregado pela rede americana Arby's ao longo de sua atuação no Brasil. Em síntese, os casos investigados indicam claramente a diferença entre França e Brasil na escolha do tipo de franchising, o que deve decorrer das condições de crédito em cada país.

Um dado adicional que corrobora a maior relevância comparativa do franchising brasileiro na captação de recursos pode ser obtido comparando-se a prática organizacional na abertura de capital entre as redes de franquias atuantes no Brasil e na França. Dentre as 454 redes membros da Associação Brasileira de Franchising (ABF), listadas no Guia Oficial 2003 da ABF, apenas 27 redes declararam ser S.A., o equivalente a $6 \%$ da amostra. Em contrapartida, no 
mercado francês, $72 \%$ das redes membros da Federação Francesa de Franquias (FFF) declararam, em 2001, ser S.A., referindo-se a 77 das 107 redes catalogadas no Guia 2002 da FFF. Do total das redes brasileiras que declararam ser S.A., $30 \%$ provêm do setor de serviços especiais, $22 \%$ do segmento de alimentação (como as redes Bom Grillê, Casa do Pão de Queijo e Dunkin’Donuts), 15\% do setor de vestuário e $11 \%$ do segmento de beleza \& saúde. Os $22 \%$ restantes dividem-se entre redes de cosméticos \& perfumarias, móveis \& decoração, informática e veículos.

Dados secundários apontam ainda que muitas das redes internacionais com atuação no mercado brasileiro, diferentemente do registrado em outros países, não costumam optar pela abertura de seu capital no Brasil. Neste sentido, vale destacar o posicionamento diferenciado da rede McDonald's no Brasil que, ao contrário do observado na França e nos EUA, é uma empresa de capital fechado. Similarmente, a rede francesa de lavanderia 5 À Sec não abriu seu capital no mercado brasileiro, em contraposição ao observado na França. Um dos poucos contra-exemplos é o Dunkin'Donuts, rede americana, que mantém no Brasil a abertura de capital registrada internacionalmente.

Continuando a análise comparada dos mecanismos de governança identificados no estudo multicaso (franquia total, parcial, locação de gerência e hierarquia), outra importante distinção refere-se ao provimento de incentivos contra o problema de risco moral tanto de esforço (moral hazard on shirking) quanto de qualidade (moral hazard on quality). Ao guardar a essência do franchising, o franqueado parcial ou de locação de gerência, mesmo sob um nível subótimo, quando comparado ao contrato de franquia total, revela-se comparativamente mais incentivado que um gerente de loja com rendimentos fixos em trabalhar tão intensamente quanto o desejado pelo franqueador. Este maior incentivo contribui para a redução das chances de um comportamento oportunista do franqueado em trapacear no desempenho de suas funções (Lafontaine, 1992; Lafontaine \& Raynaud, 2002; Norton, 1988; Rubin, 1978) e, consequentemente, nos custos de monitoramento e de controle da comercialização.

Apesar de o franchising incentivar os gestores locais a aumentar o seu nível de esforço no desempenho de suas funções, a transferência dos direitos residuais de controle de sua unidade aos franqueados, por meio da cobrança de taxas fixas, pode vir justamente a incentivá-los a buscar o aumento do lucro da unidade, em detrimento do lucro de toda a rede. Em particular, o franqueado pode aumentar seus ganhos, ao prover um serviço de menor custo, mesmo que em desacordo com os padrões de qualidade idealizados pelo franqueador, o que aumenta os riscos de perda do valor da marca franqueada. Estes riscos devem ser comparativamente mais acentuados no contrato de franquia total, a não ser que, 
em adição ao esquema de pagamento sob este formato, o franqueado se comprometa com a realização de investimentos altamente específicos em sua unidade (Azevedo \& Silva, 2001).

Nestes termos, em detrimento de ganhos no controle e gerenciamento da comercialização, a verticalização, comparativamente à franquia total, deve proporcionar maiores ganhos na proteção e valorização da marca franqueada, em função dos menores incentivos do gestor local em subinvestir em qualidade (moral hazard de qualidade, vide Tabela 1). Adicionalmente, ao garantir ao franqueador o controle sobre o ponto de venda, os contratos de franquia parcial e de locação de gerência previnem que ex-franqueados utilizem o local de sua unidade na exploração de uma atividade similar ou concorrente ao do franqueador, beneficiando-se, conseqüentemente, da clientela e de todo o conhecimento adquirido. Com o intuito de atenuar estes riscos, observa-se que os contratos de franquia total costumam ser salvaguardados por cláusulas de não concorrência ex-post $t^{(18)}$. Ademais, os contratos de franquia parcial e de locação de gerência também devem reduzir os custos legais de um rompimento unilateral por parte do franqueador, ao reduzir os investimentos específicos realizados pelo franqueado.

Uma forma de conciliar os ganhos no controle e no gerenciamento da comercialização com maior proteção e valorização da marca franqueada é por meio da operacionalização de rede mista (unidades franqueadas e lojas próprias), sobretudo alocando as unidades franqueadas em regiões fisicamente distantes das unidades operacionalizadas pelo franqueador. As lojas próprias devem contribuir para a redução da assimetria informacional existente entre as partes, permitindo ao franqueador avaliar melhor o desempenho de seus franqueados no exercício de suas funções.

A despeito dessa relação, chama a atenção o fato de os franqueadores atuantes no Brasil não explorarem por completo a diversidade dos contratos de franquia, como se identifica na França, veja Tabela 2. No Brasil, as lojas próprias são tipicamente combinadas com um único tipo de contrato, via de regra a franquia convencional. Na França, ao contrário, observa-se o emprego de um portfólio mais complexo: lojas próprias e franquia convencional conjuntamente com a franquia parcial e/ou locação de gerência, esta última destinada aos potenciais franqueados com restrições financeiras.

A proposição empírica deste artigo é que as diferenças observadas entre os dois países são decorrentes da incerteza jurisdicional. Há razoável consenso sobre a ineficiência do sistema judiciário brasileiro e suas consequiências nos arranjos econômicos ${ }^{(19)}$. Esta característica do ambiente institucional brasileiro tem implicações diretas sobre as escolha das estruturas de governança, em especial 
na escolha do portfólio do contrato de franquia: convencional, parcial e de locação de gerência, em face das lojas próprias. A incerteza jurisdicional brasileira é a principal razão por que os franqueadores internacionais não adotam no Brasil a mesma estratégia organizacional de seus outros mercados. Dunkin'Donuts, The Nuty Bavarian e Arby's, por exemplo, não exploram no Brasil a diversidade de contratos de franquia característica de sua atuação em outros mercados. No Brasil, essas companhias fazem uso exclusivo da estrutura dual de franquia convencional e integração vertical (vide Tabela 2).

É interessante notar que o único franqueador internacional que replica no Brasil as suas escolhas de formas organizacionais - o McDonald's - enfrentou uma série de disputas judiciais que o levaram a reduzir drasticamente a proporção de lojas franqueadas em relação às lojas próprias. Como usual em suas operações por todo o mundo, o McDonald's detém sempre e em qualquer hipótese o controle sobre o ponto comercial, locando ou sublocando-o a seus franqueados por algo em torno de 10 a $20 \%$ do faturamento bruto da unidade, em adição a um valor fixo, fora as demais taxas, como royalties e taxa de publicidade. Diferentemente, porém, do observado em outros países, caso da França, o McDonald's não emprega no Brasil o contrato de locação de gerência, descartando todo e qualquer candidato, cujo capital próprio disponível não atenda a $40 \%$ do investimento inicial. Na França, além de as restrições financeiras serem significativamente menores (25\% do capital inicial), o McDonald's pode vir a conceder, por um período de 13 a 36 meses, o contrato de locação de gerência. Nestes termos, do total mínimo a ser investido por um franqueado brasileiro (550 mil dólares, incluindo a taxa de franquia), no máximo $60 \%$ podem ser financiados, enquanto um franqueado francês pode beneficiar-se de financiamento de até $75 \%$ do investimento total (no caso da franquia parcial, no valor de 600 mil euros, fora a taxa de franquia de $45 \mathrm{mil}$ euros). Independentemente, porém, do mercado de atuação, os franqueados McDonald's devem recorrer às linhas de crédito especialmente desenvolvidas pela companhia americana junto a bancos americanos, sendo o empréstimo indexado ao dólar.

Ao contrário dos entendimentos legais americano e europeu, a legislação brasileira não possui um posicionamento bem definido a respeito da legitimidade da locação das unidades franqueadas por um valor superior ao efetuado pelo franqueador, nos casos em que ela é o principal locatário; ou por um valor superior ao de mercado, quando o franqueador é o proprietário do imóvel. Basicamente, este é o procedimento mundialmente utilizado pelos franqueadores que optam pelo contrato de franquia parcial ou de locação de gerência, sendo o ágio no aluguel justificado pelo fato de a locação não incluir apenas o terreno, mas também construções e melhoramentos no imóvel (Barroso, 2002). Este cenário de 
incertezas seria determinante para a escolha dos principais nomes do franchising mundial alterarem no Brasil sua tradicional política internacional de expansão, deixando de praticar a franquia parcial e/ou a locação de gerência em detrimento do contrato convencional, optando, assim, pela transferência no mercado brasileiro da integralidade dos custos de instalação a seus franqueados, até mesmo no que se refere ao controle do ponto comercial.

A posição do McDonald's em sustentar no Brasil a sua estratégia internacional de expansão vem gerando sérios conflitos entre a companhia e seus franqueados brasileiros. O estopim da crise ocorreu em 1996, quando o McDonald's partiu para uma acelerada estratégia de expansão no mercado nacional, o que, na visão dos franqueados, teria culminado na canibalização da rede, expressa em uma queda de $29,5 \%$ na venda mensal média por restaurante (Ferraz, 2000). A este respeito, vale a ressalva de que o recebimento, por parte do franqueador, de uma taxa inicial de adesão ao sistema de cada novo franqueado poderia induzir o franqueador a buscar a multiplicação de suas unidades. No caso específico do McDonald's, chama a atenção, ainda, o fato de a companhia cobrar uma nova taxa de franquia, em sua integralidade, por ocasião da renovação contratual, prática não observada entre outras redes. Embasando esta discussão, Ferraz (2000) aponta que, diferentemente de anos anteriores, entre 1996 e 2000, o número de restaurantes cresceu mais do que o faturamento global da rede, resultando em maior disputa entre os próprios franqueados.

A partir de 1999, com a desvalorização do real em face do dólar, a situação de conflitos se teria agravado, uma vez que as dívidas assumidas pelos franqueados no financiamento de suas unidades, atreladas à moeda americana, reduziram drasticamente a atratividade do negócio, colocando aqueles franqueados que ainda não haviam quitado suas dívidas em maiores dificuldades financeiras. Ferraz (2000) ilustra este quadro, estimando que no ano de 2000 cerca de $76 \%$ dos franqueados McDonald's haviam aderido ao sistema em 1998. Agravando ainda mais a situação dos franqueados brasileiros, tem-se o esquema de pagamento praticado pelo McDonald's.

Em decorrência justamente das lacunas do entendimento legal brasileiro quanto à prática de sublocação de unidades, o McDonald's passou a se envolver no Brasil em uma série de onerosos processos judiciais (Lazzarini \& Ebert, 2004). De acordo com Correa (2003), ao longo dos processos judiciais, a maioria dos franqueados em litígio depositam em juízo os valores relacionados aos royalties, taxas de publicidade e de aluguel (calculados com base em seu valor de mercado e não no estipulado contratualmente), o que contabilizaria, segundo cálculos do McDonald's, um montante de $\mathrm{R} \$ 75$ milhões. 
Ao aumentar os custos do franqueamento de seu sistema no Brasil, o quadro de conflitos entre o franqueador e seus franqueados resultou em maior interesse comparativo por parte do McDonald's pela verticalização de sua rede no mercado brasileiro, guiando, assim, a ajustes no percentual de lojas próprias, conforme ilustra a Figura 1 abaixo.

\section{Figura 1: Evolução do Percentual de Lojas Próprias Operacionalizado pelo McDonald's na França, no Brasil e no Mundo}

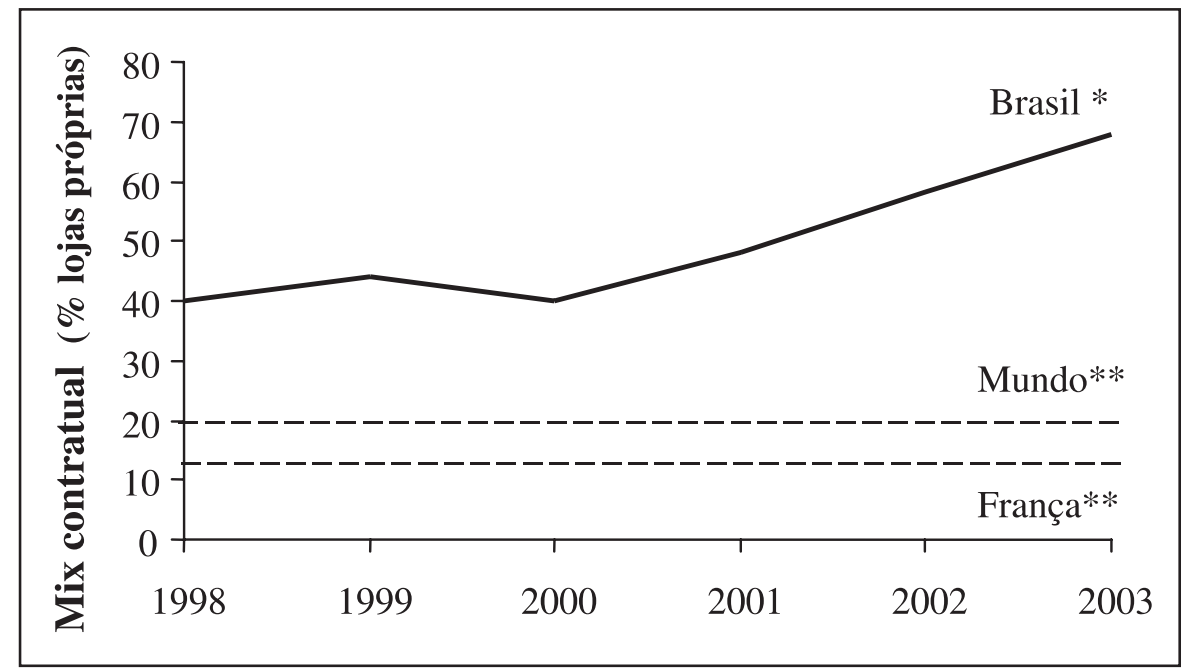

* Previsão de estabilidade, em torno de 70\%, para os próximos anos. ** Estimativa da rede. Fonte: Baseado em dados primários e em Correa (2003).

O detalhamento do caso McDonald's corrobora a proposição derivada dos demais casos, segundo a qual as diferenças na escolha de formas plurais em redes de franquias na França e no Brasil decorrem das diferenças nos respectivos ambientes institucionais, em particular pela maior incerteza quanto ao tratamento que o judiciário brasileiro confere aos contratos de franchising. Como regra geral, os franqueadores internacionais reduzem a diversidade de formas de franchising, quando atuam no Brasil, optando pela franquia convencional que, adicionalmente, apresenta-se como mecanismo de contornar as restrições de crédito para a expansão da rede. No caso do McDonald's, que mantém no Brasil as mesmas formas organizacionais utilizadas na França e em seu país de origem, a diferença no ambiente institucional se manifesta no aumento do grau de integração vertical (lojas próprias) e a conseqüente redução do uso do franchising. 


\section{CONCLUSÃo}

A coexistência de formas plurais há muito desperta o interesse da literatura de franchising, que dedicou considerável esforço na análise da operação conjunta de lojas próprias e unidades franqueadas. Este artigo, embora de acordo com a importância da escolha de formas plurais em redes de franquias, procurou mostrar que a diversidade das formas contratuais no franchising não se restringe à dicotomia loja própria-unidade franqueada. Diferentemente deste padrão, tomado como pressuposto em parte relevante da literatura econômica internacional, este artigo evidencia que a relação franqueador-franqueado é regida por diferentes modalidades de contratos, a exemplo da franquia parcial e da locação de gerência. As evidências empíricas sugerem ainda que a decisão pelo design contratual e pelo leque de formatos é condicionada pelo ambiente institucional no qual a redes se inserem.

Empregando o método dos múltiplos estudos de caso, por meio de entrevistas semi-estruturadas junto aos gerentes de redes de franquias de alimentos, vinte e um estudos de caso foram conduzidos, sete na França e 14 no Brasil. A análise empírica limitou-se, assim, à perspectiva do franqueador, não tendo sido considerado o ponto de vista do franqueado, tampouco o dos fornecedores. Com o intuito de se identificar com maior precisão as possíveis relações entre variáveis do ambiente institucional e a escolha das formas plurais, procurou-se comparar casos franceses e brasileiros que compartilhassem características comuns, como o segmento de atuação, seu grau de internacionalização e estratégias empresariais. O exemplo mais claro dessa estratégia de pesquisa é a comparação das estruturas de governança empregadas pelo McDonald's em suas operações da França e no Brasil. Adicionalmente, foram utilizadas informações secundárias para caracterizar as principais diferenças entre os ambientes institucionais de França e Brasil, que foi utilizado como principal variável explicativa.

A escolha metodológica por um estudo multicaso deve conferir maior robustez à análise empírica, atenuando as limitações intrínsecas ao método de estudo de caso quanto à capacidade de generalização dos resultados e conclusões obtidos - generalização, porém em termos de proposições teóricas e não, propriamente, de inferência estatística (Eisenhardt, 1989; Yin, 1989).

Os estudos de caso em seu conjunto indicam que, diferentemente da visão corrente da literatura de franchising, as redes de franquias não se restringem a apenas duas formas organizacionais, empregando, algumas vezes, diversos tipos de contratos de franquias. Por um lado, estas evidências alimentam o debate econômico dedicado à pluralidade de formas organizacionais no gerenciamento 
de transações similares, trazendo formas organizacionais alternativas à decisão classicamente polarizada entre loja própria e franquia. Por outro lado, pode-se reforçar estudos empíricos prévios, referentes à possibilidade de conciliar, por meio da operacionalização de uma rede mista, o maior controle sobre a transação sem a perda substancial dos incentivos inerentes ao franqueamento. A combinação de lojas próprias e franqueadas, sobretudo quando harmonizados diferentes formatos, permite aos franqueadores conciliar melhor os ganhos comparativos providos pelo franqueamento de marca aos potenciais riscos de perda de seu valor, decorrentes de problemas de externalidades horizontais e verticais, no uso deste ativo intangível.

Os estudos de caso conduzidos na França e no Brasil sugerem ainda que a decisão pelo design contratual e pelo leque de formatos está condicionada ao ambiente institucional em que as redes se inserem. Enquanto no Brasil os franqueadores se restringem a apenas duas formas organizacionais, na França é comum o emprego de três desenhos contratuais, o que decorre do entendimento legal local e do risco jurisdicional. A prática por uma combinação de formatos no franqueamento, em acréscimo à definição estratégica de um percentual de lojas próprias, revela-se restrita ao franchising francês/europeu. No Brasil, a adoção deste modelo é restringida em face das lacunas inerentes ao entendimento legal nacional quanto à prática da sublocação de unidades (essência dos formatos alternativos evidenciados na França), em acréscimo às maiores restrições sofridas pelas redes à captação de recursos. De um lado, a menor eficiência do mercado de crédito do Brasil está associada ao uso mais freqüente de tipos de contratos de franquia que tenham também o papel de captar recursos de franqueados, como forma de contornar essa característica do ambiente. De outro lado, a maior incerteza jurisdicional no Brasil quanto à resolução de litígios em contratos de franquia está associada a uma redução da diversidade de formas contratuais, bem como pela maior incidência de lojas próprias e conseqüente redução da utilização de franchising

Por fim, as redes de franquias de alimentos apresentam particularidades que podem ser relevantes para a observação dos resultados deste artigo, tais como o predomínio de bens de experiência e de crença, a demanda por segurança do alimento e a dependência de esforços a montante para a garantia de padronização. Como consequiência, é desejável a realização de pesquisas adicionais que comparem as franquias de alimento com redes de outros segmentos, a fim de investigar se os resultados observados são particularidades dos sistemas agroalimentares ou se referem a fenômenos gerais. Adicionalmente, uma vez que a pesquisa que deu origem a este trabalho se baseou em entrevistas junto a franqueadores, seria desejável que pesquisas futuras incorporassem dados obtidos com os franqueados. Dessa forma, seria possível avaliar as motivações que levam 
à escolha do franqueado pelas variedades de contratos de franquia e, assim, explorar mais profundamente a escolha do portfólio de formas organizacionais no franchising.

\section{Artigo recebido em 12.11.2005. Aprovado em 28.06.2006.}

\section{Notas}

${ }^{1}$ Embora o termo taxa de comunicação possa mostrar-se mais adequado sob a perspectiva mercadológica, taxa de publicidade é o termo tradicionalmente empregado na literatura internacional dedicada aos contratos de franquia, referindo-se também à nomenclatura empregada sob a ótica jurídica, como, por exemplo, na legislação brasileira que regula os contratos de franquia.

${ }^{2}$ A cobrança dos royalties também pode ser efetuada de forma indireta. Nestes casos, mesmo quando não previsto contratualmente o pagamento de taxa calculada com base no faturamento da unidade franqueada, esta pode advir da cobrança pelo franqueador de um sobre-preço nos insumos adquiridos pelo franqueado (Lafontaine, 1992, p. 264).

${ }^{3} \mathrm{O}$ problema de como induzir que os atores econômicos ajam conforme o interesse de seu contratante é denominado na literatura como problema da agência (agency problem), sendo analisado à luz da relação entre agente e principal. Sob esta relação, um indivíduo (principal) contrata os serviços de outro (agente) para a realização de determinadas atividades. Desde que o esforço empregado pelo agente no exercício de suas funções determina não apenas os rendimentos do principal, mas também o seu próprio bem-estar, configura-se, inevitavelmente, uma divergência de interesses, de forma que o nível de esforço que maximiza os interesses do agente deverá ser sempre inferior ao que desejaria o principal. A concretização de um comportamento oportunista pós-contratual (risco moral) apenas ocorrerá, contudo, diante da configuração de assimetria informacional: situação em que uma das partes não consegue facilmente (sem custos) observar as ações de sua contraparte (Milgrom, P., \& Roberts, J. (1990). Bargaining influence costs, and the organization of economic activity. In J. Alt \& K. Shepsle (Eds.). Perspectives on positive political economy. New York: Cambridge University Press).

${ }^{4} \mathrm{O}$ lucro residual é expresso pela diferença entre o faturamento obtido na atividade franqueada e a totalidade de custos incorridos pelo franqueado, incluindo os pagamentos relativos ao contrato de franquia: combinação de diferentes taxas, a exemplo dos royalties e taxa de publicidade.

${ }^{5}$ Vide por exemplo Rubin (1978); Norton (1988); Lafontaine (1992); Lafontaine e Raynaud (2002).

${ }^{6}$ A impossibilidade de assegurar a custo zero que o agente tome a decisão ótima para os interesses coletivos gera os custos de informação assimétrica; ou os custos de agência (agency costs) (Jensen, M. C., \& Meckling, W. H. (1976). Theory of the firm: managerial behavioral, agency costs, and capital structure. Journal of Financial Economics, 3(4), 305-360). Como componentes dos custos de agência destacam-se o pagamento de multas contratuais por parte dos agentes (Jensen \& Meckling, 1976) bem como as despesas incorridas pelo principal no controle e monitoramento das ações de seus agentes (Jensen \& Meckling, 1976), fator que tende a tornar inviável uma dispersão geográfica verticalizada (Rubin, 1978).

${ }^{7}$ Na literatura, o problema de formas plurais (Bradach, J. L., \& Eccles, R. (1989). Price, authority, and trust. Annual Review of Sociology, 15, 97-118; Bradach, J. L. (1997). Using the plural form in 
the management of restaurant chains. Administrative Science Quarterly, 42, 276-303; Coughlan, A. T., Anderson, E., Stern, L. W., \& El-Ansary, A. I. (2002). Canais de marketing e distribuição (6.ed). Porto Alegre: Bookman.) é também referenciado como mix contratual (Azevedo \& Silva, 2001; Azevedo, P. F., Silva, V. L. S., \& Silva, A. G. A. (2002). Contractual mix in food franchising. Conference of the International Society for New Institutional Economics, Cambridge, MA, 6. Recuperado em 04 agosto, 2006, de http://www.isnie.org, Bai, C. E., \& Tao, Z. (2000b). Contractual mix in franchising as a mechanism for public-good provision. Journal of Economics \& Management Strategy, 9(1), 85-113) ou ainda como distribuição dual (Bai \& Tao, 2000a). As denominações 'formas plurais' e 'mix contratual' são aqui preferidas para o melhor expressar a idéia de um portfólio de estruturas governadas pela firma, na qual a composição loja própria e unidade franqueada é um caso particular.

${ }^{8}$ Vide por exemplo Hennart, J. F. (1993). The swollen middle: a mix of market and hierarchy. Organization Science, 4(4), 529-547.

${ }^{9}$ A utilização do símbolo '>>' por Williamson, O. E. (1985). The economic institutions of capitalism. London: Free press, para definir a escolha de estruturas de governança decorre dessa limitação cognitiva, que gera problemas de mensuração dos atributos das transações. A escolha somente é definida de modo unívoco para diferenças de especificidades de ativos grandes o bastante para suplantarem o problema de mensuração.

${ }^{10}$ Conceito introduzido por Akerlof, G. A. (1970). The market for 'Lemons': quality uncertainty and the market mechanism. Quartely Journal of Economics, 84, 488-500, que mostra que a incerteza sobre a qualidade dos produtos reduz os incentivos para se comercializar produtos de qualidade superior. Nesse caso, franqueadores de qualidade superior seriam eliminados do mercado.

${ }^{11}$ Em contraposição, as teses de existência de um mix contratual transitório mostram que alguma condição básica, como reputação, informação ou acesso a crédito, altera-se endogenamente, com o passar do tempo.

${ }^{12}$ Esta idéia está originalmente presente em Argyres, N., \& Liebeskind, J. P. (1999). Contractual commitments, bargaining power, and governance inseparability: introducing history into Transaction Cost Theory. Academy of Management Review, 24(1), 49-63. Diferentemente do proposto por Williamson (1985) e mantido em trabalhos subseqüentes (Williamson, 1991; Williamson, O. E. (1996). Mechanisms of governance. New York: Oxford University Press), a escolha da estrutura de governança mais adequada não deve ser limitada ao alinhamento dos atributos de uma determinada transação, devendo ao contrário ser realizada tendo em mente todo o conjunto de transações governadas pela firma. Na visão de Argyres e Liebeskind (1999) e Argyres, N., Liebeskind, J. P. (2002). Governance inseparability and the evolution of US biotechnology industry. Journal of Economic Behavior \& Organization, 47, 197-219), a inseparabilidade de governança surge da dependência de trajetória ocasionada por escolhas passadas.

${ }^{13}$ Essencialmente, reside na barganha o problema do mix contratual estável. Azevedo, P. F. (1996). Integração vertical e barganha. Tese de doutorado, Instituto de Pesquisas Econômicas, Universidade de São Paulo, São Paulo, Brasil, indicou que uma integração vertical parcial pode afetar o retorno no caso de conflito em uma negociação (disagreement payoff), o que, por sua vez, pode afetar a apropriação do objeto sujeito à barganha. Uma integração vertical parcial serve como instrumento de barganha em uma estrutura de governança em que a quase-renda deve ser negociada entre as partes, como é o caso de uma forma híbrida. Do mesmo modo, a integração vertical parcial permite a aquisição de informação sobre o estágio produtivo subseqüente, podendo também ser utilizada como instrumento de apoio a uma estrutura de governança que pressuponha a negociação entre as partes (Riordan. M. (1990). What is vertical integration? In M. Aoki, B. Gustafsson, \& O. E. Williamson (Eds.). The firm as a nexus of treaties. London: Sage). Em ambos os casos, não há no 
argumento uma idéia de trajetória do mix contratual. Este, pelo contrário, mantém-se estável, desde que não haja alterações exógenas relevantes nas dimensões da transação. A noção de 'retornos crescentes', desenvolvida por Arthur, W. B. (1989). Competing technologies, increasing returns, and lock-in by historical events. The Economic Journal, 99, 116-131, mostra, adicionalmente, que a estabilidade do mix contratual pode ser verificada mesmo em casos em que haja mudanças significativas nas dimensões das transações.

${ }^{14}$ Veja, por exemplo, Bradach e Eccles (1989), Dant et al. (1996), Bradach (1997), Bai e Tao (2000a; 2000b), Azevedo e Silva (2001), Lafontaine, F., \& Shaw, K. L. (2001). Targeting managerial control: evidence from franchising. NBER [Working Paper Series $\mathrm{N}^{\circ}$ 8868]. National Bureau of Economic Research, Cambridge, MA, Estados Unidos; Penard, T., Raynaud, E., \& Saussier, S. (2003). Dual distribution and royalty rates in franchised chains: an empirical exploration using French data. Journal of Marketing Channels, 10(3), 5-32.

${ }^{15}$ Uma exceção é Bercovitz J. (2004). The organizational choice decision in business format franchising: an empirical test. In J. Windsperger, G. Cliquet, G. Hendrikse, \& M. Tuunanen.(Eds.). Economics and Management of Franchising Networks. New York: Springer, Berlin Heidelberg.

${ }^{16}$ Veja, por exemplo, Rubin (1978) e Lafontaine (1992).

${ }^{17} \mathrm{O}$ Brasil possui uma das mais altas taxas de juros do mundo. Fundamentos macroeconômicos são certamente parte da história para explicar esta anomalia no mercado de capitais brasileiro; mas há variáveis institucionais que não podem ser omitidas na análise. Arida, P., Bacha, E., \& Resende, A. L. (2005). Credit, interest, and jurisdictional uncertainty: conjectures on the case of Brazil. In F. Giavazzi, I. Goldfajn \& S. Herrera (Orgs.). Inflation targeting, debt, and the Brazilian experience, 1999 to 2003. Cambridge-MA: MIT Press, por exemplo, observam que o Brasil não possui um mercado de crédito de longo prazo, visto que as decisões judiciais predominantemente favorecem os devedores. Como resultado, a opção de contratos de longo prazo tende a ser descartada, uma vez que é maior a sua probabilidade de acabar na justiça. Diferentemente da realidade brasileira, o mercado de capitais na França/Europa é mais acessível. Uma imperfeição na transação entre franqueador e o mercado de capitais impõe restrições que devem ser solucionadas pelo uso da franquia convencional, funcionando como mecanismo de captação de recursos do franqueado para o franqueador. Na França, o papel do franchising como uma alternativa para captar recursos é atenuada graças ao melhor acesso do franqueador ao mercado de capitais.

${ }^{18}$ O Regulamento de Isenção no 4087 da Comunidade Européia de 1988 - diploma legal europeu de concorrência que regula indiretamente a prática do franchising - restringe para um período máximo de um ano a aplicação da cláusula pós-contratual que limite a atuação do ex-franqueado em atividade similar à do franqueador. A cláusula pós-contratual de não concorrência deve ainda ser restrita ao local e ao terreno em que o ex-franqueado exerceu suas atividades durante a vigência do contrato, bem como à condição de que ela seja indispensável à proteção do conhecimento transferido do franqueador ao franqueado. Em contrapartida, a legislação brasileira em vigor (Lei no 8.955) não delimita período máximo de vigência da cláusula pós-contratual de não concorrência; tampouco limita sua aplicação ao local e terreno em que o ex-franqueado exerceu suas atividades.

${ }^{19}$ Pinheiro, A. C. (2005). Magistrados, judiciário e economia no Brasil. In D. Zylbersztajn \& R. Sztajn (Eds.). Direito \& economia: análise econômica do direito e das organizações. Rio de Janeiro: Elsevier, em um extensivo survey, observa que as decisões judiciais brasileiras são muito lentas e tendenciosas para a parte mais fraca. Arida et al. (2005) atribuem a inexistência de um mercado de capitais brasileiro de longo prazo à deficiência das garantias judiciais oferecida aos credores. Zylbersztajn, D. \& Nadali, L. B. (2003). Tomatoes and courts: strategies of the agroindustry facing weak contract enforcement. Annual Conference of the International Society for 
New Institutional Economics, Budapest, Hungria, 7, observam que as decisões locais no agribusiness são sensíveis à forma como as cortes regionais julgam processos de litígio entre produtores e indústrias. Algumas ineficiências são consequiências de atrasos e incertezas com respeito às decisões judiciais.

\section{ReferênCIAS BibliográficAs}

Aaker, D. A. (1998).

Brand equity: gerenciando o valor da marca. São Paulo: Negócio.

Aoki, M. (1990).

Toward an economic model of the japanese firm. Journal of Economic Literature, 28(1), 1-27.

Azevedo, P. F., \&

Silva, V.L. S. (2001).

Contractual mix in brazilian franchising. Conference of the International Society for New Institutional Economics, Berkeley, CA, 5. Recuperado em 04 agosto, 2006, de http://www.isnie.org

Bai, C. E., \&

Tao, Z. (2000a).

Franchising as a nexus of incentive devices for production involving brand name [Working Paper] University of Hong Kong, China.

Barroso, L. F. (2002).

Franchising \& direito. Rio de Janeiro: Lúmen Júris.

Coase, R. (1937).

The nature of the firm. Economica, 4 . (16), 386-405.

Correa, C. (2003).

Dieta amarga. Revista Exame. Recuperado em 8 novembro, 2003, de http://portalexame.abril.com.br/ pgMain.jhtml? ch=ch06\&sc= s c $0601 \&$ pg = pgart_0601_ 071103_57220.html.

Dant, R. P.,

Paswan, A. K., \&

Stanworth, J. (1996).

Ownership redirection trends in franchising: a cross-sectoral investigation. International Journal of Entrepreneurial Behavior and Research, 2(3), 48-67.

Eisenhardt, K. M. (1989).

Building Theories from Case Study

Research. The Academy of Management Review, 14(4), 532-550.

Ferraz, E. (2000, Setembro 6).

Sinal amarelo: ter uma franquia do McDonald's não é mais garantia de sucesso. Revista Exame, (Edição 722), 34.

Gallini, N. T., \& Lutz, N.A. (1992).

Dual distribution and royalty fees in franchising. Journal of Law, Economics, \& Organization. 8(2), 471-501.

Lafontaine, F. (1992).

Agency theory and franchising: some empirical results. Rand Journal of Economics, 23(2), 263-282. 
Lafontaine, F., \&

Raynaud, E. (2002).

The role of residual claims and selfenforcement in franchise contracting. [Working Paper Series No 8868]. National Bureau of Economic Research, Cambridge, MA, Estados Unidos.

Lazzarini, S., \&

Ebert, K. J. K. (2004).

McDonald's: conflitos com franqueados no Brasil. Mimeo, IBMEC, São Paulo, SP, Brasil.

Michael, S. C. (2000).

Investments to create bargaining power: the case of franchising. Strategic Management Journal, 21(3), 497-514.

Norton, S. W. (1988).

An empirical look at franchising as an organizational form. Journal of Business, 61(1), 197-217.
Rubin, P.H. (1978).

The theory of the firm and the structure of the franchise contract. Journal of Law and Economics, 21(2), 223-233.

Scott, F.A. (1995).

Franchising vs. Company ownership as a decision variable of the firm. Review of Industrial Organization, 10(1), 69-81.

Williamson, O. E. (1991).

Comparative economic organization: the analysis of discrete structural alternatives. Administrative Science Quarterly, 36(2), 269-96.

Yin, R. K. (1989).

Case study research: design and methods. London: SAGE. 